\title{
sciendo
}

\section{Change management within companies}

\author{
Dorel PARASCHIV \\ Bucharest University of Economic Studies, Romania \\ dorel.paraschiv@ase.ro \\ Maria NIȚU \\ Bucharest University of Economic Studies, Romania \\ maria.nitu@rei.ase.ro \\ Mihai SAVIN \\ Bucharest University of Economic Studies, Romania \\ Mihai.Savin@apanovabucuresti.ro
}

\begin{abstract}
The environment in which a company operates is diverse and demanding, as there are unnoticed variables. In order to ensure success in the transformation process of a company's management, leaders need to take into account certain factors that will help the company gain competitive advantage. The ability of companies to adapt, start or implement a change will depend to a large extent on the human resources and skills, attitudes and knowledge they hold. So change is an essential component of the evolution process of companies that put effort, time and resources into implementing an advantageous strategy, but, on the other hand, transformation can be the decay of an organization. For such a strategy, managers need to balance all relevant aspects of the organization and the outside, so that they can position themselves to the current realities of the business environment. This article highlights the importance of change management for the companies, the challenges that they encounter in this process, as well as the main models and theories of change management.
\end{abstract}

Keywords: Change Management, Manager, Company, Technology, Challenges

\section{Introduction}

From the point of view of management, change is the transformation of a company's strategy, as a result of a fluctuation in environmental, technology, structure, and personal factors. Changing management approaches are numerous and diverse, with a wide range, but the management of the transformation process varies greatly, from one company to another. This article presents the process of management change, the challenges it encounters internally and externally, as well as the possibility of calling to certain specialists, consultants or even their own managers.

Changes that will take place in an organization must be properly managed and carefully planned by implementing a concrete plan of action and, in particular, by involving staff who may be affected by these transformations. It is important to achieve a realistic, measurable and achievable change, as change management can produce at company level an improvement in leadership and employee communication, augmenting productivity.

\section{Literature review}

From the perspective of theory and practice, management is one of the most important conditions generating economic performance in an organization. The literature in this field has focused on studying the role and place of management in the economy of an organization 
and clarifying the situations in which it can influence commercial and economic conduct. Therefore, management can be treated through the following hypotheses:

- Scientifically - "explaining the nature and traits of the management process, contrary to an organized set of knowledge specific to the formation of managers and the orientation of the activities "(Burdus, Popa, 2018, p. 17). Thus, management can be expressed through three situations: the theoretical (relationship management processes), the methodological (to establish instruments, the principle that can explain the mechanism of exercising the management system and the managerial functions) and the practice (achieving the objectives set at maximum efficiency and effectiveness).

- Practice - is a practical activity that is based on intuitive elements (expressiveness, talent, particular ability of the manager), being a social and conscious process. From the point of view of practical work, management is an intellectual work whereby an individual leader, manager - determines other people (who are subordinates / executors) to perform certain activities in order to achieve the objectives. Therefore, this is a process of work in which the manager "by virtue of tasks, competences and responsibilities takes decisions influencing the decisional and operational behavior of other people" (Verboncu, Nicolescu, Popa, 2011, p. 9)

- Decision / Activity Center - represented by an individual or a group of individuals with a certain formal authority, through which decisions are made that can influence the behavior and activity of others. Several policy boards can be identified within an organization: "the Board of Directors (CA), the General Assembly of the Shareholders (AGA), the Steering Committee (CD), the Managing Director, etc., which, according to an Organization and Functioning Regulation (ROF) and job descriptions, have decision-making powers "(Burdus, Popa, 2018, p. 17).

Classical management processes consist of a system of stages that determines the objectives, organizes and coordinates the activities, efforts and actions undertaken, trains the personnel involved in the achievement of the objectives, checks the way of carrying out the activities and regulates the way the whole system works. The activities of the management process, carried out by any, leader, manager, regardless of the field in which they operate or by the hierarchical level, can be grouped according to theory into management functions. From the perspective of traits, the management process is characterized by interdependence, continuity (the activities of the organizations are continuous), cyclicality (the repetition of some activities made by the manager in practical action), effectiveness and progressivity (the transition from one cycle to another, to improve this process).

The concept of "change / transformation" is not a novelty of the active society, but it is older than humanity and includes all aspects of the way the world evolves. Thus, Change has become essential for society, both from a personal perspective and within organizations, and the knowledge of the process of change is a defining element of an efficient management that will ensure the competitiveness of the organization. The change can take place independently of the will of man, but regardless of the causes of production, this transformation must be known, investigated and controlled if objectives are to be achieved. Thus, the management of change represents "the whole of the processes of planning, organizing, coordinating, training and control of some measures of replacing, modifying, 
transforming or transforming in the form and continuity of the company or subsystems of the company, in order to increase its efficiency and competitiveness" (Popescu, 2013, p. 371). Also, according to E. Burdus, "organizational changes are responses to certain external forces, or may be determined by certain endogenous variables, such as the tendency of managers to apply different specific methods / techniques" (Burdus, 2003, p. 371). The process of change management is very important for the growth and sustainability of any organization (Lozano, 2013), the purpose being the progress form the original and actual state to the necessary condition/state. According to the European Commission, the change represents an opportunity that must be organized, well managed and the most important, predicted (European Commission, 1998).

Change management has become an interconnected process which can be applied to all departments in an organizational development: finance, human resource, management, production, etc. This process can be bottom-up or top-down and if in the second condition are involved the stakeholders and the change starts from bottom the change in the company will be permanent. Several practitioners and authors have different opinion regarding the stages of the change management:

- Beckhard and Harris in 1977 presented 3 steps: The Current State, The Transition State and the Future State

- Lynn A. Isabella's Model presented 4 steps: Anticipation, Confirmation, Culmination and Aftermath

- Kanter at all suggested three steps: The Change Strategists, the Change Implementers and the Change Recipients

- Grimley et al and Prochaska et al. suggested 4 steps: Pre-contemplation, Contemplation, Action and Maintenance.

The Change Management Best Practice according to the USAID (United States Agency International Development) are the following: 1. Establish a vision, 2. Involve senior leadership, 3. Develop a change management plan, 4. Engage stakeholders, 5. Communication at all levels, 6. Create infrastructure to support adoption, 7. Measure progress, which can be seen in the next figure. 


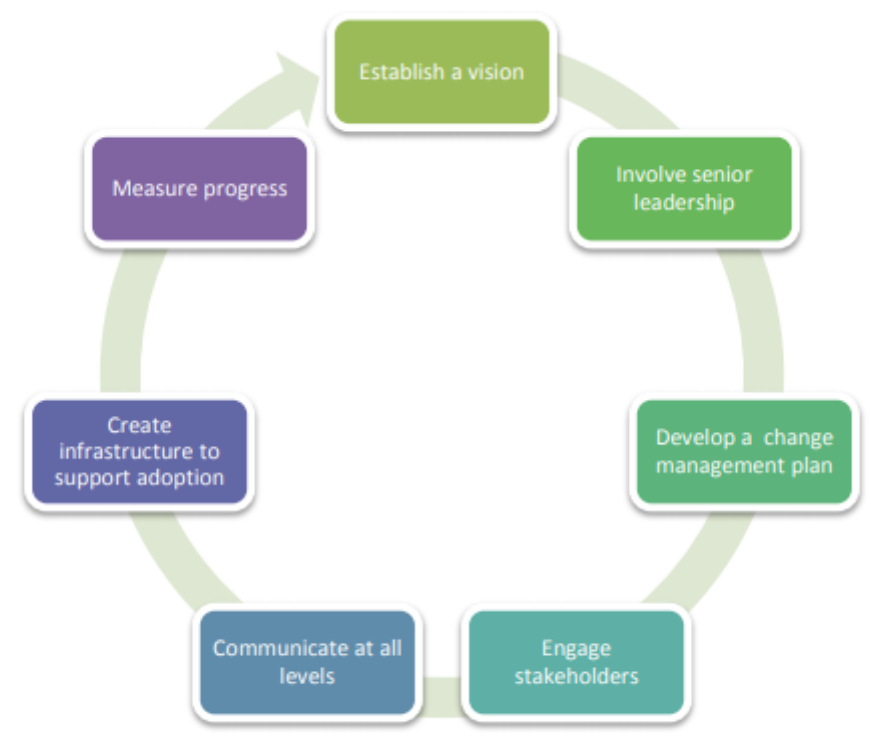

PICBE $\mid 628$

Figure 1: Change Management best practice (USAID, 2015)

The first step, Establish a vision, it should be simple, relevant and clear. The second, Involve a senior leadership, is a fundamental step, in achieving a long lasting change into the organization which requires involvement and commitment form the staff and the stakeholders. The next step (Develop a change management plan) is one of the most important because the process of change management starts now and demands a detailed plan for action. Engage stakeholders represents the implication of the stakeholders in this process which is essential in reducing barriers and creating a sense of ownership (Fernandez and Rainey, 2006). The next step, Communication at all levels, presents the crucial importance of the process of communication as well as the frequent of the communication that should be held at all levels. The sixth step, Create infrastructure to support adoption, presents the importance of the supportive infrastructure in company/organization which includes the Procedures and the System, the organizational structure and its Policies. The last step, Measure Progress, needs to be continues and built in the process of change.

The permanent change of the environment in which organizations operate is defined by certain trends and is subject to challenges that put pressure on the process of transformation. Thus, the main tendency / challenge is represented by the globalization process, which encourages competition, competitiveness, attracting changes in the markets (volume of mergers of the big companies, the single market created by the European Union), but also changes in the external environment, internal and cultural organizations. The second component targets the environment, the discovery of technologies, clean and alternative materials, the reduction of raw materials consumption and pollution. Thus, there is an obligation for organizations to carry out intervention and preventive measures that respect the principles of environmental protection. In recent years, specific trends have emerged: the number of women involved in management activity has increased, health 
concerns (stress relieving, eradication of diseases, consumption of natural products), accelerating innovation and cost reduction, employees' and change the job, etc.

Also, the challenges faced by the company have also expanded in field of technology, working conditions, the explosion of knowledge, changes in the workforce, the rapid development of products. Evolution in the field of technology determines the change in the nature of work so that employees can use their capabilities to operate with more complex equipment. For example, in many Canadian, Japanese and American assembly workshops and enterprises, there is a tendency for automation and the use of artificial intelligence. In this situation, managers need to have technical knowledge and understand the processes through which different sectors are related (sales, production, human resources, financial), have communication skills and skills in interpersonal relationships, embrace change to perform a effective activity in a field in full transformation, and especially, they have to prove that they understand how the whole system works. We are witnessing an evolution of technology in all sectors that cause change at organizational level, and managers need to lead and control this phenomenon so that the effects are favorable to all (external and internal) participants.

Working conditions have become essential for staff, especially when employees are open to professional and personal learning, and meeting these needs is a factor that puts pressure on company change. Thus, improving working conditions with the objective of reducing absenteeism and stimulating employees implies a number of organizational changes, decision-making, motivation processes, etc.

Workforce changes report an increase in the share of women working full-time in a company, which will entail a number of changes in their work. In addition, there is an increase in the share of intellectual work that leads to change and training among managers, as they will face different problems with staff selection, engagement and motivation. The explosion of knowledge represents a major phenomenon of the current society and requires the establishment of major changes within the companies through the coordinated actions of the managers, among them: the creation of new ideas and their transposition into services and products to be assimilated by the company, the discovery and the spread of knowledge in the field of communication, the development of the ability to lead and to work with all types of employees.

In addition to the challenges mentioned above, companies and managers may face resistance to the change process, embracing different forms, from open (explicit) resistances that can be expressed through strikes, negligence in work, sabotage or diminishing work productivity, to hidden (implicit) resistances that can be manifested by resignations, delays, morale and loss of motivation. These resistances can be specific to the individual generated by his / her habits within the company, fear of ignorance, attention, selective memory and economic rationality that implies financial security of the staff or resilient at the organization level, such as limited capital resources, personnel and time, organizational structure, immobility of capital and threats to the power and influence of individuals within the organization and organizational culture. In order to implement the change within the company, the manager has to plan this process so that the transformation is carried out in a controlled and coordinated manner, depending on the proposed objectives. There are authors who consider change management "the process of identifying sources of resistance to change and the provision of ways to overcome them" (Kotter, Schlesinger, 1979). 
The literature of organizational change management has divers theories and models of change and we have identified 3 about which we are going to present and discuss, models that are suitable in this era as well:

1. Kurt Lewin : Three Step Approach to Planned Change

2. John Kotter's Eight Step Process for Leading Change

3. ADKAR Model: Awareness, Desire, Knowledge, Ability, Reinforcement Kurt Lewis: Three Step Approach to Planned Change was proposed in the 1940s and included the following steps: Unfreezing, Changing and Freezing.

- Unfreezing, this first step represents the awareness of the company/organization regarding the change and involves moving a department, individuals and if it is necessary an entire business, the aim being to motivate.

- Changing, the second step, known as the transition step is more comprehensive because change requires time, and the employees can become uncertain about the effects of this transformation, the key solution being the permanent communication.

- Freezing, this last step present the need for stability after the changed have occurred. When the changes are acknowledged and once they become the new norm of the organization, the individuals form new work relationship and become content regarding their new schedules and practices.

This model in used in order to explain the phenomenon of change management in the organizational, individual or societal level. There are some inference in this model because the transformation can be achieved, controlled, focused, but the learning process I s behavior and individuals have different methods of learning. If we encounter a resistance to the change we can remove it by planning in advance, and through a strong leadership and management.

John Kotter's Eight Step Process for Leading Change is another emblematic model of change management, based on a couple of his studies regarding the private sector organization, in which he explained that the process of management change that occurs in the organization is divided into different stages and requires a certain and considerable time. In the next figure, we can see the eight steps process for leading change according to John Kotter. 
Implementing and Sustaining

New Ways

Monitor uptake and govemance

('Sustaining Change)

Enabling and Engaging the Organization

Prepare people to work in the new erwirconment? Training?

Demanstrate how the change will work (COrientation?

Explain how the change will affect individuals (Familianization")

Setting the Climate for Change

Create an understanding of

the rationale \&

opportunities ("Positioning

Change?

\section{Making it stick}

7. Consolidating gains and building on success

6. Generating and celebrating

short-term wins

5. Enabling employees to make the

change

4. Communicating the change and mobilizing commitment

\section{Developing a vision and strategy}

2. Developing and being part of a guiding coalition

Creating a sense of shared need and urgency

\section{Figure 1. John Kotter's Eight Step Process for Leading Change}

Source: Change Management best practice guide, p. A-1 https://www.usaid.gov/sites/default/files/documents/1868/597saj.pdf

As we can see in this figure, the Kotter's Eight Step Process for Leading Change is divided in 3 large segments as followed (USAID, 2015):

- Setting the Climate for Change includes the first three steps: Creating a sense of shared need and urgency, Developing and being part of a guiding coalition AND Developing a vision and strategy

- Enabling and Engaging the Organization: Communicating the change and mobilizing commitment, Enabling employees to make the change and Generating and celebrating short-term wins

- Implementing and sustaining New Ways: Consolidating gains and building on success and Making it stick

The two initial stages of the Kotter's model are the most representative: creating a sense of urgency and creating the guiding coalition (Saima Tabassum Siddiqui, 2017). This approach helps leaders and manager to follow the right framework previously implementing the change. On the other hand, this model has some downsides: it is a model top down, it is mechanical (in the process of change are involved a group of people) and this model can become overwhelming.

The ADKAR Model: Awareness, Desire, Knowledge, Ability, Reinforcement was introduced by Prosci, in 1999, which is a change management research company. This model is based on a analysis from approximate 300 firms that have experienced a significant change initiatives. According to Prosci, this model is used by the managers in order to diagnose the staff resistance to change, to help the employees through the process of change and to create 
a plan for the professional development during this period of change. The next figure, presents the four elements of the ADKAR Model.

\begin{tabular}{|c|c|}
\hline ADKAR Elements & Factors Influencing Success \\
\hline $\begin{array}{l}\text { Awareness } \\
\text { of the need for change }\end{array}$ & $\begin{array}{l}\text { - A person's view of the current state } \\
\text { - How a person perceives problems } \\
\text { - Credibility of the sender of awareness messages } \\
\text { - Circulation of misinformation or rumors } \\
\text { - Contestability of the reasons for change }\end{array}$ \\
\hline $\begin{array}{l}\text { Desire } \\
\text { to support and participate in the change }\end{array}$ & $\begin{array}{l}\text { - The nature of the change (what change is and how it will impact each person) } \\
\text { - The organizational or environmental context for the change (his or her perception of the } \\
\text { organization or environment that is subject for change) } \\
\text { - Each individual person's situation } \\
\text { - What motivates a person (those intrinsic motivators that are unique to an individual) }\end{array}$ \\
\hline $\begin{array}{l}\text { Knowledge } \\
\text { of how to change }\end{array}$ & $\begin{array}{l}\text { - The current knowledge base of an individual } \\
\text { - The capability of this person to gain additional knowledge } \\
\text { - Resources available for education and training } \\
\text { - Access to or existence of the required knowledge }\end{array}$ \\
\hline $\begin{array}{l}\text { Ability } \\
\text { to implement required skills and behavior }\end{array}$ & $\begin{array}{l}\text { - Psychological blocks } \\
\text { - Physical capabilities } \\
\text { - Intellectual capability } \\
\text { - The time available to develop the needed skills } \\
\text { - The availability of resources to support the development of new abilities }\end{array}$ \\
\hline $\begin{array}{l}\text { Reinforcement } \\
\text { to sustain the change }\end{array}$ & $\begin{array}{l}\text { - The degree to which reinforcement is meaningful and specific to the person impacted by the change } \\
\text { - The association of the reinforcement with actual demonstrated progress or accomplishment } \\
\text { - The absence of negative consequences } \\
\text { - An accountability system that creates an ongoing mechanism to reinforce the change }\end{array}$ \\
\hline
\end{tabular}

Figure 2. The ADKAR Model

Source: Change Management best practice guide, p. A-3 https://www.usaid.gov/sites/default/files/documents/1868/597saj.pdf

The first element, awareness, presents the importance of ensuring that each member of the company is aware and also, understands the need for the change. In order to achieve the second step, desire, it is very important to work with the team, to present the negative consequences if no action is taken and the need for the change. In this stage, it will have a huge impact if it is explain what benefits each one can have, such as: career advancement, job security, financial incentives. In this step, must be given the knowledge to the team members or what they have to do in order to achieve the change. The next step, knowledge or how to make the change presents the resources available for training and education and the capacities of the persons in order to gain and manifest additional knowledge. The ability of implementing required behavior and skills, such as: physical and intellectual capability, the time needed In order to develop the necessary skill. The last step, reinforcement, represents the process in which the change is sustained.

This model is goal oriented and is focusing on the activities and actions in achieving results, being effective for integrating the concepts of management into the process of change management.

\section{Methodology}

The research method used in the article is quantitative. Thus, I use the historical method to review the evolution of the management process and change management. With the help of 
synthesis, I presented the 3 most relevant models of change management (Kurt Lewin's 3 stage Model of Change, Kotter's eight step process and ADKAR Model), as well as the main challenges (internal and external) to which a company is subjected when deciding to implement change management .

\section{Results and discussions}

It can be said that the business landscape of the 21st century is represented by novelties, trends, events, innovation, all of which are happening at an alert pace, surprising the majority of leaders and managers. The only constant is change and companies, organizations, businesses need to be prepared to cope and face sudden transformation.

The environment in which a company operates is diverse and demanding, as there are unnoticed variables. In order to ensure success in the transformation process of a company's management, leaders need to take into account certain factors that will help the company gain competitive advantage. So, as mentioned above, assessing the operational environment and understanding it will enable the firm to develop according to the changes it imposes. Managers, along with company staff, must take account of specialist analyzes and have a sensitive and open attitude to environmental oscillations. Also, in conducting this change should be a person professionally and personally empowered. The way in which the designated person will deal with this change will have to take into account the organizational context and market characteristics.

The ability of companies to adapt, start or implement a change will depend to a large extent on the human resources and skills, attitudes and knowledge they hold. It is important for staff to keep their value, and even more, to improve their skills, and this process is a long one. In this manner, the company will be able to overcome the resistance of employees to change. Regarding the resistance coming from within the organization, the manager must have a coherent strategy change, be adaptable to organizational culture and specificity, advantageous to both parties (employees and leadership) and feasible. There is also the possibility to call on specialists, external consultants who will facilitate the process of transformation of the company, based on a diagnosis of the situation of the organization, they will be able to provide real and feasible improvements, as well as assisting in the implementation processes.

The determinant factors of the process of change are elements that belong to a situation and by their appearance, action or existent, they trigger a transformation at the organization level. These factors come from inside of a company (at the organization or its subdivision) and from the outside (the environment in which the organization operates and evolves). Therefore, the decision regarding the change will be made on the basis of studies carried out in the general environment or macro medium based on the PEST / PESTLE analysis and also based on a study of the specific environment (competitors, customer, suppliers, etc.) and consultations conducted at the management level and employees level, so that they know the strengths and weaknesses of the company. In order to assimilate and understand the necessity of the change process, companies have the opportunity to call a specialist or consultants from inside or outside the company who can provide service diagnostics, improvement proposals and assisted implementation of proposals so that the transition is smooth and the actors involved will understand the usefulness of this 
phenomenon. Thus, we find 3 categories of specialist in this field: consultants, specialists in various fields and managers, who can facilitate the process of change.

In conclusion, change is an essential component of the evolution process of companies that put effort, time and resources into implementing an advantageous strategy, but, on the other hand, transformation can be the decay of an organization. For such a strategy, managers need to balance all relevant aspects of the organization and the outside, so that they can position themselves to the current realities of the business environment.

The successful implementation of the process of transformation represents an interesting and very serious challenges due to the nature of opportunities and threats which can occur and rarely there is an appropriate answer or strategy to follow.

\section{References}

Andrei Dobrescu, 2016, Comportament organizationa, Editura Pro Universitaria, Bucuresti portamentului angajatilor ,Editura Polirom, Change Management best practice guide, p. A-3 https://www.usaid.gov/sites/default/files/documents/1868/597saj.pdf

Doina I. Popescu, 2013, Comportament organizational, Editura ASE, Editia a II-a, Bucuresti, p. 371

Eugen Burdus, Ion Popa, 2018, Fundamentele managementului organizatiei, Editura Pro Universitaria, Editia a III-a, Bucuresti, p. 17

Eugen Burdus, Gheorghita Caprarescu, Armenia Androniceanu, 2008, Managementul schimbarii organizationale, Editura Economica, Bucuresti

George Moldovean, 2005, Analiza si comportament organizational, Editura Economica, Bucuresti

Ion Verboncu, Ovidiu Nicolescu, Ion PopA, Eduard Ceptureanu, Sebastian Ceptureanu, 2011, Schimbarea organizationala prin reengineering, Editura ASE, Bucuresti, p.9

John Kotter, 2009, Forta schimbarii, Cum difera lidershipu-ul de management, Editura Publica

Jonas Ridderstrale, Mark Wilcox, 2010,Revitalizarea corporatiei. Cum reusesc liderii sa produca schimbarea, Editura Publica

Peter Makin, Charles Cox, 2006, Schimbarea in organizatii, optimizarea com

Saima Tabassum Siddiqui, A critical review of change management Strategies and Model, International Journal of Advanced Research (IJAR), 2017 